\title{
PENGARUH MODEL PEMBELAJARAN CONCEPTUAL UNDERSTANDING PROCEDURES (CUPS) DENGAN TEKNIK PROBLEM SOLVING TERHADAP PENGUASAAN KONSEP FISIKA PESERTA DIDIK DI SMAN 7 MATARAM
}

\author{
Charisma Permadi Zulmi*, Hairunisyah Sahidu, Jannatin ‘Ardhuha \\ Program Studi Pendidikan Fisika, Universitas Mataram \\ *Email: permadi.zulmi97@gmail.com
}

DOI: http://dx.doi.org/10.29303/jpft.v5i2.1375

\begin{abstract}
This study aims to determine the effect of the learning model of conceptual understanding procedures (CUPS) with problem solving techniques on mastering the concept of physics of students for optical instrument material in SMAN 7 Mataram in the academic year 2018/2019. This type of research used quasi-experimental design with untreated control group design with pre-test and post-test. The population is all students of XI MIPA class with taking the research sample using purposive sampling technique, so that students of XI MIPA 3 class were selected as the experimental class and XI MIPA 2 class as the control class. Data collection techniques used the initial test (pre-test) and final test (posttest) with multiple choice questions as many as 20 items. To test the research hypothesis used parametric statistical tests, namely the t-test with pre-test and post-test. From the calculation results obtained by the value of t-count of 4.42 which value is greater than t-table which is 2.008 at a significant level of $5 \%$, so it can be concluded that the null hypothesis (HO) is rejected. Thus, there is the influence of the learning model of conceptual understanding procedures (CUPS) with problem solving techniques on mastering of physics concepts of students of XI MIPA class at SMAN 7 Mataram in the academic year $2018 / 2019$.
\end{abstract}

Keywords: conceptual understanding procedures (CUPs); problem solving; concept mastery

PENDAHULUAN

Pendidikan yang berkualitas merupakan cerminan dari suatu bangsa yang maju dan berdaulat. Di era milenial saat ini, pendidikan di Indonesia dituntut untuk semakin maju dan berkembang, baik dari kualitas guru, kemampuan berpikir peserta didik, maupun fasilitas yang mendukung proses pembelajaran. Upaya yang diterapkan pemerintah untuk meningkatkan kualitas pendidikan yaitu dengan menetapkan kurikulum 2013 dengan tuntutan peserta didik harus lebih aktif dalam kegiatan belajar di sekolah. Selain itu, tujuan diterapkannya kurikulum 2013 untuk memperbaharui kurikulum sebelumnya dan berusaha menyadarkan peserta didik untuk melek teknologi, terutama untuk generasi milenial yang hidup di era industri saat ini (Depdiknas, 2006).

Penerapan kurikulum 2013 sejauh ini berjalan cukup baik, namun terdapat berbagai macam permasalahan pada proses pembelajaran sehingga perlu diadakan perbaikan agar kurikulum yang diterapkan dapat berjalan lebih optimal. Permasalahan dalam proses pembelajaran dapat terjadi pada seluruh mata pelajaran, salah satunya pada mata pelajaran fisika. Permasalahan yang sering terjadi pada mata pelajaran fisika yaitu rendahnya tingkat penguasaan konsep dari peserta didik. Menurut Fitriani et al. (2017), rendahnya penguasaan konsep fisika peserta didik disebabkan karena selama proses belajar mengajar berlangsung banyak peserta didik yang kurang memperhatikan apa yang dijelaskan oleh guru atau hanya ada beberapa yang memperhatikan. Peserta didik juga kurang aktif bertanya tentang konsep-konsep yang kurang dimengerti. Peserta didik cenderung melakukan aktivitas lain daripada memperhatikan guru yang sedang mengajar, hal ini terjadi karena ketertarikan peserta didik terhadap pelajaran fisika sangat kurang, selain itu peserta didik menganggap bahwa fisika adalah mata pelajaran yang 
sulit dan membosankan karena penuh dengan persamaan-persamaan.

Untuk dapat meningkatkan penguasaan konsep fisika dari peserta didik, guru berusaha mengaktifkan peserta didik secara individu maupun kelompok. Keaktifan dari peserta didik bisa ditingkatkan dengan menggunakan berbagai macam model ataupun metode pembelajaran. Tetapi, hal tersebut tidak dapat terealisasi apabila kemampuan dari guru dalam menyampaikan materi dan membimbing peserta didik masih kurang. Dengan demikian, peran guru dalam pembelajaran tetap menjadi hal yang utama agar mampu meminimalisir masalah rendahnya penguasaan konsep fisika peserta didik.

Berdasarkan hasil wawancara dengan beberapa peserta didik di SMA Negeri 7 Mataram, terdapat berbagai macam permasalahan pada proses pembelajaran fisika salah satunya yaitu pembelajaran yang digunakan hanya mengandalkan kemampuan seorang guru saja, sementara untuk keaktifan dari peserta didik tidak terlalu diperhatikan. Hal ini menunjukkan bahwa penerapan kurikulum yang berlaku saat ini belum optimal, akibatnya kemampuan peserta didik untuk memahami konsep-konsep suatu materi pembelajaran masih rendah. Rendahnya penguasaan konsep fisika yang dimiliki peserta didik di SMA Negeri 7 Mataram dibuktikan dengan nilai ulangan semester yang mereka dapatkan masih di bawah KKM (Kriteria Ketuntasan Minimal) atau $<75$, hasil ini diperoleh berdasarkan wawancara dengan guru fisika.

Permasalahan ini tentunya memerlukan solusi, salah satu cara yang dapat dilakukan yaitu dengan melakukan pengkajian untuk bisa mengaktifkan peserta didik dan meningkatkan penguasaan konsepnya. Berkaitan dengan hal itu, peneliti memberikan solusi untuk menerapkan model pembelajaran conceptual understanding procedures (CUPs) yang bertujuan untuk membantu meningkatkan penguasaan konsep fisika peserta didik.

Alasan lain yang mendasari peneliti memilih model CUPs karena selain dapat membantu meningkatkan konsep fisika peserta didik, model pembelajaran CUPs juga mampu mengajak peserta didik untuk lebih aktif berpikir dalam memecahkan suatu permasalahan, hal ini sejalan dengan penelitian Lakuntu et al. (2015), yang menyatakan bahwa model CUPs dapat meningkatkan pemahaman konsep peserta didik dibandingkan dengan model pembelajaran konvensional dengan metode ceramah. Selain itu Fitriani et al. (2017), juga mengatakan bahwa model pembelajaran conceptual understanding procedures (CUPs) merupakan model pembelajaran yang dapat mengaktifkan peserta didik secara langsung. Lebih lanjut juga dikatakan bahwa model pembelajaran CUPs tepat digunakan untuk membuat pembelajaran menjadi student centered dan guru tetap menjadi pembimbing sekaligus fasilitator dalam perkembangan peserta didik dalam mengemukakan pengetahuan dan pendapatnya.

Penelitian dari Ismawati et al. (2014), menyatakan bahwa "model pembelajaran CUPs merupakan model pembelajaran yang terdiri atas serangkaian kegiatan pembelajaran dan bertujuan untuk meningkatkan pemahaman konsep peserta didik". Kemudian menurut Anggreni et al. (2013), dalam penelitiannya mengatakan bahwa "CUPs merupakan suatu model pembelajaran yang bertujuan untuk membantu meningkatkan pemahaman konsep yang dianggap sulit oleh peserta didik". Sementara menurut Prastiwi et al. (2014), "model pembelajaran conceptual understanding procedures (CUPs) merupakan model pembelajaran yang 
dirancang untuk membantu perkembangan pemahaman peserta didik menemukan konsep yang sulit". Dari pemaparan beberapa pendapat di atas, dapat disimpulkan bahwa model pembelajaran conceptual understanding procedures (CUPs) adalah model pembelajaran yang bertujuan untuk meningkatkan penguasaan konsep peserta didik melalui tahapan atau langkah-langkah yang sistematis. Tahapan dalam pembelajaran CUPs dikatakan sistematis karena dapat mengaktifkan peserta didik secara individu maupun kelompok.

Menurut Ismawati et al. (2014), terdapat empat faktor yang mempengaruhi keberhasilan penerapan pembelajaran dengan pendekatan konstruktivis, yaitu:

a. Memberikan informasi awal sebelum pembelajaran, peserta didik dikenalkan pada materi yang dibahas.

b. Menggali konsep awal peserta didik yang berkaitan dengan materi pelajaran.

c. Merancang desain eksperimen yang akan dilakukan, dan

d. Melakukan kegiatan laboratorium, dapat berupa kegiatan eksperimen dan pembuatan laporan hasil eksperimen.

Model pembelajaran CUPs juga diperkuat nilai-nilai cooperative learning dan peran aktif peserta didik dalam belajar. Untuk dapat meningkatkan pemahaman dan penguasaan konsep dari peserta didik, diperlukan kerjasama yang baik antara peserta didik saat diskusi kelompok, agar seluruh anggota kelompok dapat menguasai konsep-konsep yang berkaitan dengan materi yang diajarkan (Mariana, 2009). Hal ini sesuai dengan penelitian dari Anggreni et al. (2013), yang menyatakan bahwa "pembelajaran yang berlandaskan pada penguasaan konsep secara menyeluruh akan membuat pengetahuan yang dimiliki lebih bertahan lama diingatan dan hal tersebut dapat mengoptimalkan hasil belajar".
Dalam penelitiannya, Ismawati et al. (2014) juga menyatakan bahwa model pembelajaran CUPs dilakukan dalam tiga fase yaitu fase kerja individu, fase kerja kelompok, dan fase presentasi hasil kerja kelompok. Fase pertama diawali dengan penyajian demonstrasi sederhana oleh guru dengan tujuan untuk merangsang pemikiran peserta didik. Pada fase pertama, peserta didik dibiasakan dengan kegiatan mengamati dan bertanya yang sesuai dengan pembelajaran kurikulum 2013. Fase kedua adalah fase kerja kelompok, peserta didik bekerja secara berkelompok dalam kegiatan eksperimen dan dilanjutkan dengan kegiatan diskusi kelompok, peserta didik membahas hasil kegiatan eksperimen kelompok dan mengerjakan lembar kerja kelompok. Pada fase ketiga, masing-masing kelompok mempresentasikan hasil diskusi, guru bertindak sebagai fasilitator dan mengevaluasi hasil kerja kelompok.

Penerapan model pembelajaran CUPs akan berjalan dengan baik apabila dikombinasikan dengan teknik yang sesuai. Teknik yang dapat digunakan untuk mengaktifkan peserta didik dalam menemukan konsep dan memecahkan suatu permasalahan fisika salah satunya adalah teknik problem solving. Hal ini sesuai dengan penelitian dari Rahono et al. (2014), yang menyatakan bahwa teknik problem solving dapat membantu peserta didik dalam meningkatkan pemahaman, daya kreativitas serta inovasi terhadap materi pelajaran. Kemudian menurut Shoimin (2014), juga mengatakan bahwa "problem solving adalah teknik yang dapat menstimulasi peserta didik dalam berpikir yang dimulai dari mencari data sampai merumuskan kesimpulan sehingga peserta didik dapat mengambil makna dari kegiatan pembelajaran". Selain itu, penerapan teknik problem solving dapat membuat peserta didik menjadi lebih aktif dan kreatif, terutama dalam menyelesaikan suatu 
permasalahan fisika yang berkaitan dengan konsep.

Teknik problem solving juga sangat ideal digunakan pada peserta didik yang belum sama sekali mengetahui cara penyelesaian soal, sehingga peserta didik diharapkan mampu menggunakan teknik ini untuk dapat menganalisis suatu permasalahan sampai pada tahap penyelesaiannya. Menurut Siswanto et al. (2014), terdapat beberapa kriteria pemilihan bahan pelajaran untuk teknik problem solving yaitu "bersifat familiar dengan peserta didik, berhubungan dengan kepentingan orang banyak, mendukung tujuan atau kompetensi yang harus dimiliki peserta didik sesuai kurikulum yang berlaku, dan sesuai dengan minat peserta didik, sehingga peserta didik merasa perlu untuk mempelajarinya".

Siswanto et al. (2016), juga mengemukakan bahwa terdapat tahapan dalam menerapkan teknik problem solving, yaitu:

1. Merumuskan masalah

Dalam merumuskan masalah kemampuan yang diperlukan adalah kemampuan mengetahui dan merumuskan suatu masalah.

2. Menelaah masalah

Dalam menelaah masalah kemampuan yang diperlukan adalah menganalisis dan merinci masalah yang diteliti dari berbagai sudut.

3. Menghimpun dan mengelompokkan data Menghimpun dan mengelompokkan data adalah mengumpulkan data dalam bentuk bagan, gambar, dan lain-lain sebagai bahan pembuktian hipotesis.

4. Pembuktian hipotesis

Dalam pembuktian hipotesis kemampuan yang diperlukan adalah kecakapan menelaah dan membahas data yang telah terkumpul.

5. Menentukan pilihan pemecahan masalah dan keputusan
Dalam menentukan pilihan pemecahan masalah dan keputusan kemampuan yang diperlukan adalah kecakapan membuat alternatif pemecahan, memilih alternatif pemecahan dan keterampilan mengambil keputusan.

Pembelajaran dengan menggunakan model conceptual understanding procedures (CUPs) yang dikombinasikan dengan teknik problem solving menuntut peserta didik untuk selalu aktif dalam kegiatan pembelajaran dan mampu memecahkan permasalahan dengan baik. Sehingga diharapkan perpaduan model dan teknik ini dapat meningkatkan penguasaan konsep fisika dari peserta didik. Selain itu, peneliti bermaksud untuk memperkenalkan model conceptual understanding procedures (CUPs) dengan teknik problem solving sebagai alternatif yang dapat membantu dan mempermudah guru dalam menyampaikan materi pada mata pelajaran fisika.

\section{METODE PENELITIAN}

Jenis penelitian yang digunakan yaitu kuasi eksperimen dengan desain untreated control group design with pre-test and posttest. Terdapat beberapa variabel dalam penelitian ini yaitu variabel bebas, variabel terikat, dan variabel kontrol. Variabel bebasnya model pembelajaran conceptual understanding procedures (CUPs) dengan teknik problem solving yang diterapkan pada kelas eksperimen, sementara untuk variabel bebas yang diterapkan pada kelas kontrol yaitu model pembelajaran konvensional. Variabel terikatnya penguasaan konsep fisika peserta didik, dan variabel kontrolnya berupa materi pembelajaran, guru, tujuan pembelajaran, dan cara penilaian.

Populasi dalam penelitian ini seluruh peserta didik kelas XI MIPA SMA Negeri 7 Mataram tahun pelajaran 2018/2019 yang berjumlah 210 orang. Teknik pengambilan sampel yang digunakan purposive sampling. 
Berdasarkan pertimbangan khusus dari peneliti, maka sampel yang digunakan adalah peserta didik kelas XI MIPA 3 dan XI MIPA 2 dengan jumlah masing-masing 25 dan 27 orang.

Instrumen penilaian yang digunakan berupa tes penguasaan konsep fisika untuk materi alat-alat optik. Adapun bentuk tes penguasaan konsep fisika yang digunakan yaitu tes pilihan ganda dengan jumlah 30 butir soal. Indikator penguasaan konsep yang diukur yaitu ranah kognitif $\mathrm{C}_{1}$ (mengingat), $\quad \mathrm{C}_{2} \quad$ (memahami), $\quad \mathrm{C}_{3}$ (menerapkan), $\quad \mathrm{C}_{4} \quad$ (menganalisa), $\mathrm{C}_{5}$ (mengevaluasi), dan $\mathrm{C}_{6}$ (menciptakan).

Sebelum digunakan, instrumen terlebih dahulu diujicobakan untuk mengetahui validitas, reliabilitas, daya beda, dan taraf kesukarannya. Berdasarkan hasil uji coba instrumen, sebanyak 20 soal pilihan ganda yang diterima sebagai instrumen penelitian karena telah memenuhi 4 kriteria pengujian. Uji prasyarat analisis data yang digunakan yaitu uji homogenitas dan uji normalitas. Uji homogenitas menggunakan persamaan uji-F dan uji normalitas menggunakan persamaan Chi-kuadrat. Kemudian untuk uji hipotesis menggunakan uji statistik parametrik yaitu uji-t with pretest and post-test dengan taraf signifikan $5 \%$. Untuk mengetahui peningkatan penguasaan konsep fisika peserta didik per sub materi digunakan pula uji $\mathrm{N}$-gain. $\mathrm{N}$-gain juga berfungsi untuk mengetahui perbedaan signifikan hasil perolehan nilai dari peserta didik kelas eksperimen dengan kelas kontrol.

Sebelum diberikan perlakuan pada peserta didik kelas XI MIPA 3 dan XI MIPA 2 , terlebih dahulu peneliti memberikan tes awal (pre-test) penguasaan konsep fisika. Hal ini disesuaikan dengan desain penelitian yang digunakan. Selain itu, tujuan diberikan tes awal (pre-test) untuk mengetahui kemampuan awal yang dimiliki peserta didik relatif sama atau tidak. Kemudian, pada kedua kelas diberikan perlakuan selama tiga kali pertemuan dengan alokasi waktu setiap pertemuan selama 90 menit atau 2 jam pelajaran untuk materi alat-alat optik. Sub materi alat-alat optik yang disampaikan terdiri dari pemantulan cahaya, pembiasan cahaya, dan alat-alat optik.

\section{HASIL DAN PEMBAHASAN}

Hasil yang diperoleh dari penelitian ini adalah hasil pre-test, hasil post-test, hasil uji homogenitas, hasil uji normalitas, dan hasil uji hipotesis. Hasil pre-test penguasaan konsep fisika pada kelas eksperimen maupun kelas kontrol termasuk dalam kategori rendah. Hal ini terlihat dari nilai rata-rata tes yaitu 20 untuk kelas eksperimen dan 23 untuk kelas kontrol. Nilai rata-rata yang diperoleh peserta didik pada kelas eksperimen maupun kelas kontrol jika dibandingkan dengan nilai KKM (Kriteria Ketuntasan Minimal) dikategorikan tidak tuntas. Hal ini disebabkan karena peserta didik pada kedua kelas belum diberikan materi pelajaran yang terkait, sehingga memperoleh nilai rata-rata yang tergolong rendah.

Untuk mengetahui pengaruh dari perlakuan yang diberikan, peserta didik pada kedua kelas diberikan post-test dengan materi, jumlah, dan bobot soal yang sama seperti pre-test. Berdasarkan analisis data post-test, nilai rata-rata peserta didik pada kedua kelas sama-sama mengalami peningkatan.

Peserta didik kelas eksperimen memperoleh nilai rata-rata lebih tinggi yaitu 77, sedangkan peserta didik pada kelas kontrol memperoleh nilai rata-rata yaitu 67 . Hasil pre-test dan post-test penguasaan konsep kelas eksperimen dan kelas kontrol dapat dilihat pada Tabel 1 . 
Tabel 1. Hasil pre-test dan post-test Penguasaan Konsep Fisika Kelas Eksperimen dan Kelas Kontrol

\begin{tabular}{clcccl}
\hline \multirow{2}{*}{ Tes } & \multicolumn{1}{c}{ Kelas } & $\begin{array}{c}\text { Jumlah } \\
\text { Peserta } \\
\text { Didik (N) }\end{array}$ & $\begin{array}{c}\text { Nilai } \\
\text { Maks. }\end{array}$ & $\begin{array}{c}\text { Nilai } \\
\text { Min. }\end{array}$ & Rata-rata \\
\hline \multirow{2}{*}{ Pre-test } & Eksperimen & 25 & 40 & 5 & 20 \\
& Kontrol & 27 & 45 & 5 & 23 \\
\multirow{2}{*}{ Post-test } & Eksperimen & 25 & 95 & 60 & 77 \\
& Kontrol & 27 & 85 & 50 & 67 \\
\hline
\end{tabular}

Tabel 2. Hasil Uji Homogenitas dan Normalitas Kelas Eksperimen dan Kelas Kontrol

\begin{tabular}{|c|c|c|c|c|c|}
\hline \multicolumn{6}{|c|}{ Uji Homogenitas } \\
\hline \multirow{2}{*}{ Kelas } & \multicolumn{2}{|c|}{ Pre-Test } & \multicolumn{2}{|c|}{ Post-test } & \multirow{2}{*}{ Keterangan } \\
\hline & $F_{\text {hitung }}$ & $F_{\text {tabel }}$ & $F_{\text {hitung }}$ & $F_{\text {tabel }}$ & \\
\hline $\begin{array}{c}\text { Eksperimen } \\
\text { Kontrol }\end{array}$ & 1,041 & 1,95 & 1,184 & 1,96 & Homogen \\
\hline \multicolumn{6}{|c|}{ Uji Normalitas } \\
\hline \multirow[b]{2}{*}{ Kelas } & \multicolumn{2}{|c|}{ Pre-Test } & \multicolumn{2}{|c|}{ Post-test } & Keterangan \\
\hline & $\chi_{\text {hitung }}^{2}$ & $\chi_{\text {tabel }}^{2}$ & $\chi_{\text {hitung }}^{2}$ & $\chi_{\text {tabel }}^{2}$ & \\
\hline Eksperimen & 4,389 & 11070 & 1,733 & 11070 & Terdistribusi \\
\hline Kontrol & 9,689 & $11,0 / 0$ & 1,862 & $11,0 / 0$ & normal \\
\hline
\end{tabular}

Berdasarkan Tabel 1, nilai rata-rata post-test peserta didik pada kedua kelas sama-sama mengalami peningkatan jika dibandingkan dengan nilai rata-rata pada pre-test. Untuk mengetahui perbedaan peningkatan yang dialami oleh kedua kelas secara kuantitatif serta pengaruh dari model yang diberikan, maka perlu dilakukan uji hipotesis. Syarat untuk melakukan uji hipotesis, data yang diperoleh adalah homogen dan terdistribusi normal seperti yang terlihat pada Tabel 2, nilai $F_{\text {hitung }}$ dan $\chi_{\text {hitung }}^{2}$ baik pre-test maupun post-test pada kelas eksperimen dan kelas kontrol lebih kecil dari $F_{\text {tabel }}$ dan $\chi_{\text {tabel }}^{2}$. Sehingga data yang diperoleh homogen dan terdistribusi normal. Dengen demikian, uji hipotesis yang digunakan yaitu uji-t with pre-test and post-test.

Dengan menggunakan uji-t diperoleh nilai $\mathrm{t}_{\text {hitung }}=4,42$ sedangkan nilai $\mathrm{t}_{\text {tabel }}=$ 2,008 . Hal ini menunjukkan bahwa $t_{\text {hitung }}$ lebih besar dari pada $t_{\text {tabel }}$, yang berarti $\mathrm{H}_{0}$ ditolak, sehingga dapat disimpulkan bahwa model pembelajaran conceptual understanding procedures (CUPs) dengan teknik problem solving berpengaruh terhadap penguasaan konsep fisika peserta didik kelas XI MIPA SMA Negeri 7 Mataram tahun pelajaran 2018/2019.

Sebagai tindak lanjut dari analisis data, dilakukan uji $\mathrm{N}$-gain untuk mengetahui peningkatan nilai per sub materi pada kedua kelas. Uji normalized gain (Uji N-gain) juga bertujuan untuk mengetahui tingkat signifikansi peningkatan penguasaan konsep fisika peserta didik setelah diberikan perlakuan. Uji ini merupakan selisih skor tes awal dan tes akhir yang dibuat dalam bentuk persentase. Menurut Hake (1999), persentase peningkatan penguasaan konsep fisika peserta didik dibagi dalam 3 kategori, yaitu tinggi $(g>70 \%)$, sedang $(30 \% \leq$ $g \leq 70 \%)$, dan rendah $(g<30 \%)$.

Hasil yang didapatkan adalah persentase nilai $\mathrm{N}$-gain pada kelas eksperimen selalu lebih besar daripada kelas kontrol. Perolehan nilai rata-rata $\mathrm{N}$-gain pada kelas eksperimen sebesar $73 \%$ dan di kelas kontrol sebesar 54\%, maka dapat disimpulkan bahwa peningkatan penguasaan konsep fisika peserta didik pada kelas eksperimen lebih baik daripada kelas 
kontrol. Skor tertinggi pre-test dan post-test peserta didik kelas eksperimen dan kelas kontrol terdapat pada sub materi pemantulan cahaya. Untuk sub materi pemantulan dan pembiasan cahaya pada kelas eksperimen termasuk dalam kategori tinggi, sedangkan untuk sub materi alat-alat optik masuk dalam kategori sedang.

Sementara untuk kelas kontrol, keseluruhan sub materi termasuk dalam kategori sedang. Nilai rata-rata pre-test dan post-test sub materi pemantulan cahaya pada kedua kelas lebih tinggi dari yang lainnya, hal ini disebabkan karena kedalaman dan keluasan materi pada sub materi pemantulan cahaya lebih rendah dibandingkan sub materi pembiasan cahaya dan alat-alat optik, sehingga peserta didik lebih mudah memahami pelajaran karena peneliti dapat menyampaikan materi secara lebih maksimal. Peningkatan penguasaan konsep fisika peserta didik per sub materi dapat dilihat pada Tabel 3 berikut:

Tabel 3. Hasil Uji N-gain Penguasaan Konsep Fisika Peserta Didik Kelas Eksperimen dan Kelas Kontrol

\begin{tabular}{|c|c|c|c|c|c|}
\hline \multirow{3}{*}{ Kelas } & \multirow{2}{*}{\multicolumn{3}{|c|}{$\begin{array}{l}\text { N-gain Per Sub Materi Penguasaan } \\
\text { Konsep }\end{array}$}} & \multirow{3}{*}{$\begin{array}{c}\text { N-gain } \\
\text { Total }\end{array}$} & \multirow{3}{*}{ Kriteria } \\
\hline & & & & & \\
\hline & $\begin{array}{c}\text { Pemantulan } \\
\text { Cahaya }\end{array}$ & $\begin{array}{c}\text { Pembiasan } \\
\text { Cahaya }\end{array}$ & $\begin{array}{l}\text { Alat-alat } \\
\text { Optik }\end{array}$ & & \\
\hline Eksperimen & $78 \%$ & $71 \%$ & $70 \%$ & $73 \%$ & Tinggi \\
\hline Kontrol & $70 \%$ & $52 \%$ & $41 \%$ & $54 \%$ & Sedang \\
\hline
\end{tabular}

Berdasarkan Tabel 3, terlihat persentase peningkatan penguasaan konsep fisika lebih baik terjadi pada kelas eksperimen untuk tiap indikatornya. Peningkatan tersebut dapat terjadi karena pada kelas eksperimen diberikan perlakuan dengan menerapkan model pembelajaran conceptual understanding procedures (CUPs) dengan teknik problem solving. Dampak positif penerapan model pembelajaran CUPs pada kelas eksperimen yaitu dapat menambah keaktifan peserta didik dalam belajar. Hal ini disebabkan karena peserta didik terlibat langsung selama proses pembelajaran yang diawali dengan mengerjakan lembar kerja individu yang berkaitan dengan materi yang akan diajarkan. Saat mengerjakan lembar kerja individu, peserta didik juga difasilitasi oleh guru dengan menggunakan teknik problem solving, sehingga proses pengerjaan lembar kerja menjadi lebih terarah dan peserta didik dituntut untuk membuat hipotesis dari materi yang akan diajarkan.
Tidak hanya aktif secara individu, peserta didik juga terlibat aktif secara kelompok dalam melakukan eksperimen, diskusi, dan presentasi hasil diskusi. Kemudian, peserta didik dapat mengumpulkan data untuk dapat membuktikan hipotesis yang telah dibuat pada saat mengerjakan lembar kerja individu. Sehingga, pembelajaran menjadi lebih bermakna dengan lebih banyak melibatkan peserta didik dalam kegiatan belajar. Dengan demikian, antusias dan minat belajar dari peserta didik juga semakin bertambah.

Hal ini sesuai dengan yang dikemukakan oleh Hikmah et al. (2014) tentang model pembelajaran conceptual understanding procedures (CUPs) dapat meningkatkan aktivitas dan hasil belajar peserta didik. Selain itu, Ibrahim et al. (2017) dalam penelitiannya membuktikan bahwa penerapan model pembelajaran conceptual understanding procedures (CUPs) berbantuan LKPD berpengaruh 
positif terhadap kemampuan pemecahan masalah fisika peserta didik SMA. Begitupun dengan Rahono et al. (2014), yang menyatakan bahwa teknik problem solving dapat membantu peserta didik dalam meningkatkan pemahaman, daya kreativitas serta inovasi terhadap materi pelajaran.

Model pembelajaran conceptual understanding procedures (CUPs) dapat berpengaruh baik dalam meningkatkan penguasaan konsep fisika karena peserta didik lebih mudah memahami konsep yang diajarkan sebab mereka sendiri yang menemukan konsep tersebut. Selain itu, peserta didik juga dapat merasakan manfaat pembelajaran, sebab masalah-masalah yang diselesaikan berkaitan dengan kehidupan nyata. Penerapan model ini semakin efektif ketika dipadukan dengan teknik problem solving. Teknik problem solving digunakan agar peserta didik lebih mudah dalam menyelesaikan permasalahan yang diberikan. Selain itu, teknik problem solving juga dapat merangsang peserta didik berpikir dan bertindak kreatif, sehingga peserta didik terbiasa untuk memecahkan masalah yang dihadapi.

Hal lain yang perlu diketahui bahwa model pembelajaran conceptual understanding procedures (CUPs) memiliki kelemahan dimana model ini memerlukan waktu yang cukup lama dalam pelaksanaannya. Sedangkan untuk teknik problem solving sendiri tentunya memiliki kelemahan juga yaitu keterbatasan dalam menentukan suatu masalah, karena tidak semua pelajaran mengandung masalah yang harus dipecahkan. Jadi, sangat diperlukan kreativitas dan keterampilan guru.

\section{PENUTUP}

Berdasarkan hasil uji hipotesis, dapat disimpulkan bahwa model pembelajaran conceptual understanding procedures (CUPs) dengan teknik problem solving berpengaruh terhadap penguasaan konsep fisika peserta didik kelas XI MIPA SMA Negeri 7 Mataram tahun pelajaran 2018/2019. Model pembelajaran conceptual understanding procedures (CUPs) dengan teknik problem solving memberikan pengaruh yang lebih baik jika dibandingkan dengan model pembelajaran konvensional. Hal ini dikarenakan model pembelajaran conceptual understanding procedures (CUPs) dengan teknik problem solving mampu mengaktifkan peserta didik secara individu maupun kelompok, sehingga penguasaan konsep fisika yang dimiliki oleh peserta didik lebih optimal. Model pembelajaran conceptual understanding procedures (CUPs) dengan teknik problem solving ini dapat diterapkan untuk meningkatkan penguasaan konsep fisika peserta didik dengan mempertimbangkan beberapa hal, seperti materi yang akan digunakan dan waktu pembelajaran yang harus disesuaikan dengan kedalaman dan keluasan materi.

\section{REFERENSI}

Anggreni, K.R., Meter, I.G., \& Wiarta, I.W. 2013. Model Pembelajaran Conceptual Understanding Procedures Berpengaruh Terhadap Hasil Belajar Matematika Siswa Kelas V Sd Gugus VII Kompiang Sujana Denpasar Barat. Jurnal Sains dan Teknologi, II(4).

Depdiknas. 2006. Permendiknas No. 22 Tahun 2006 Tentang Standar Isi. Jakarta: Depdiknas.

Fitriani, N., Gunawan, \& Sutrio. 2017. Berpikir Kreatif dalam Fisika dengan Pembelajaran Conceptual Understanding Procedures (CUPs) berbantuan LKPD. Jurnal Pendidikan Fisika dan Teknologi, 3(1), 24-33.

Hake, R.R. 1999. Analyzing Change/Gain Scores.www.physics.indiani.edu/sdi /AnalyzingChange-Gain.pdf. Diakses pada tanggal 17 Juli 2019. 
Hikmah, N., Baidowi, B., \& Kurniati, N. 2014. Penerapan Model Pembelajaran Conceptual Understanding Procedures (CUPs) untuk Meningkatkan Aktivitas dan Hasil Belajar Matematika Siswa Kelas X SMA Negeri 7 Mataram. Jurnal Pijar MIPA, 9(2).

Ibrahim, Kosim, \& Gunawan. 2017. Pengaruh Model Pembelajaran Conseptual Understanding Procedures (CUPs) Berbantuan LKPD terhadap Kemampuan Pemecahan Masalah Fisika. Jurnal Pendidikan Fisika dan Teknologi, 3(1), 14-23.

Ismawati, I., Nugroho, P., dan Dwijananti, D. 2014. Penerapan Model Pembelajaran Conceptual Understanding Procedures untuk Meningkatkan Curiosty dan Pemahaman Konsep Siswa. Jurnal Pendidikan Fisika Indonesia. 10, 2223.

Lakuntu, J.K., Werdhiana, I.K., dan Muslimin, M. 2015. Penerapan Model Pembelajaran Conceptual Understanding Procedures Menggunakan Metode Eksperimen terhadap Pemahaman Konsep Hukum Newton pada Siswa Kelas X SMA Negeri 1 Palu. Jurnal Pendidikan Fisika Tadulako (JPFT) 5(1).

Mariana, M., Alit, I.M., dan Praginda, W. 2009. Hakikat IPA dan Pendidikan IPA. Bandung: Pusat Pengembangan dan Pemberdayaan Pendidik dan Tenaga Kependidikan Ilmu Pengetahuan Alam.

Prastiwi, I., Soedjoko, E., dan Mulyono, M. 2014. Efektivitas Pembelajaran Conceptual Understanding Procedures Untuk Meningkatkan Kemampuan Siswa Pada Aspek Koneksi Matematika. Kreano, Jurnal Matematika Kreatif-Inovatif, 5(1), 41-47.

Rahono, D., Sunarno, W., dan Cari, C. 2014. Pembelajaran Fisika dengan
Pendekatan Problem Solving melalui Metode Demonstrasi dan Eksperimen untuk Meningkatkan Motivasi dan Hasil Belajar Siswa. Inkuiri, 3(3).

Shoimin, A. 2014. 68 Model Pembelajaran Inovatif dalam Kurikulum 2013. Yogyakarta: Ar-Ruzz Media.

Siswanto, W., dan Ariani, D. 2016. Model Pembelajaran Menulis Cerita. Bandung: PT Refika Aditama. 